\title{
Design and Analysis on Key Components of a Novel Chili Pepper Harvester's Picking Device
}

\author{
Lei Jin ${ }^{1}$, Qin Xinyan ${ }^{1}$ and Yongcheng Chen ${ }^{*}, 2$ \\ ${ }^{I}$ Department of Power and Mechanical Engineering, University of Wuhan, Wuhan, Hubei, 430072, P.R. China \\ ${ }^{2}$ Department of Mechanical and Electrical Engineering, University of Shihezi, Shihezi, Xinjiang 832003, P.R. China
}

\begin{abstract}
The work principle of the picking device of a novel chili pepper harvester is described. A spring tooth is designed and strength check is analyzed. The stress distribution of a spring tooth is investigated by FEM simulation. The trajectory equation of spring tooth is established to determine the optimal rotate speed and translational speed of the picking roller. Finally, the optimal height of the passive roller is determined by the characteristic parameters of chili pepper plant. Using these optimization parameters, the prototype of the chili pepper harvester is developed and the picking experiment is investigated. The picking rate is $99.15 \%$, the total loss rate is $5.15 \%$, and the damaged rate is $3.22 \%$. These main optimization parameters have been reached the design requirement. These analysis provides technical support for optimized design of the chili pepper harvester and help accelerate the improvement, design and development of the chili pepper harvester.
\end{abstract}

Keywords: Chili pepper harvester, passive roller, picking device, picking roller, spring tooth.

\section{INTRODUCTION}

China is a big country of production and consumption of chili pepper. There are 28 provinces and regions of our country planting chili pepper, such as Hunan, Guizhou, Henan, Xinjiang, etc. However chili peppers have been picked manually by primarily migrant workers. These disadvantages of artificial picking are great labor intensity, low efficiency and high cost, which seriously hurts the pepper farmers' enthusiasm for production and seriously restrict the healthy development of chili pepper industrialization [1].Chili pepper harvester have not made significant progress in China. Import harvesters are very expensive. Therefore, it is of great significance to accelerate the study of chili pepper harvester, to develop with independent intellectual property rights, reasonable price and to adapt to our cropping patterns chili harvester [2].

At home and abroad the technology of wheat harvester is more mature [3]. But wheat's grain parameters is quite different with chili pepper, which makes its picking device many significant difference. In 2010, Xinjiang machinery Research Institute developed a self-propelled chili pepper harvester, achieving technology breakthroughs for the chili mechanization harvest. Picking device as an important part of the chili pepper harvester, directly affects the performance of the machine and picking quality. The picking device of chili pepper harvester consists of picking roller, spring tooth, passive roller, and other components. A cycle of its work is able to achieve picking, conveying, containing and loading.
Higher adaptability and productivity of machinery can meet different harvesting requirements.

This article introduces the work principle of the picking device of chili pepper harvester. The appropriate design scheme is determined. These key components are carried out design, modelling and simulation analysis work, which has important guiding significance for the optimization parameters of picking device.

\section{THE OVERALL DESIGN SCHEME OF PICKING DEVICE}

\subsection{The Chili Pepper's Agronomic Characteristics}

Chili pepper plants are vigorous, compact and few branches, and it has longer internodes. The height and width of chili pepper plants are $60 \sim 105 \mathrm{~cm}$ and $35 \mathrm{~cm}$, respectively. The shape of chili pepper is slender and uniform. Chili pepper is $15 \sim 20 \mathrm{~cm}$ length and its diameter is $1.2 \mathrm{~cm}$. The average weight of chili pepper is $7 \mathrm{~g}$. The distribution of the chili pepper is shown in Fig. (1).

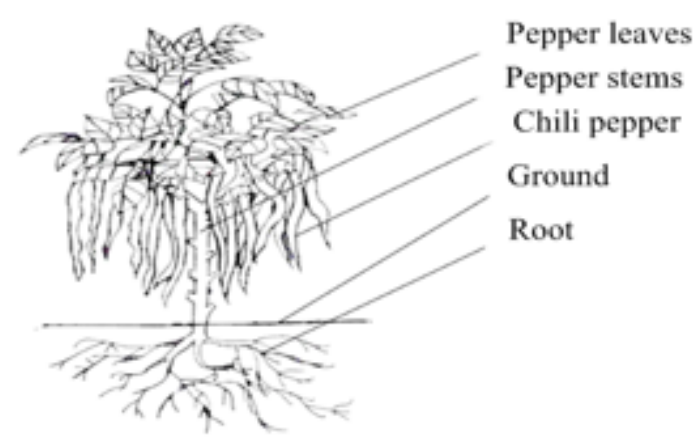

Fig. (1). Schematic diagram of the chili pepper distribution. 


\subsection{The Harvest Requirements of Chili Pepper}

\subsubsection{The Picking Height}

Chili pepper harvest should meet agricultural requirements, namely machines harvesting height should be between chili pepper plant height and width. If picking height is higher than the height of the plants, it must result in lower production net rate, because the chili pepper mainly grows in plant width location. If picking height is below the plants, the picking device will touch the ground, which causes spring tooth bend damage. Meanwhile, impurities on the ground will be bounced, which causes chili pepper mechanical impact damage.

\subsubsection{The Net Rate and Damage Rate}

Evaluating chili pepper harvesters' effect of picking chili peppers good or bad, these main parameters are the purities rate, the damaged rate and the working efficiency. The purities rate indicates the chili pepper harvest rate and is an important parameter of judging the level of harvester's technology. Drop loss rate indicates the chili peppers aren't picked by machine and the damage is caused by the equipment. Artificial picking are adopted to find the remaining chili peppers after the machine clean up the chili peppers which are lost on the stems and the ground. The damage rate refers to the damaged chili peppers account for the proportion of total harvest in the process of the adopting.

According to the conditions of GB5262 agricultural machines test, chili pepper harvesters operating standards for: purities rate $\geq 95 \%$, damage rate $\leq 3 \%$, impurities rate $\leq$ $3 \%$, total loss rate $\leq 6 \%$, tons of productivity for per hour: $7 \mathrm{~T}$ is appropriate.

\subsection{The Overall Design Scheme of Picking Device}

The United States respectively made an experimental study on expansions spiral chili harvester, tilt arbor comb chili pepper harvester and ribbon combs chili pepper harvester [4-6]. The picking parts of the arbor comb chili pepper harvester demand higher line of picking and compulsively pick on the chili seedling stem. So stems stalk and leaves fall easily with chili pepper fruit leading to excess of debris and the damage rate is larger; ribbon combs chili pepper harvester also demand higher line of picking. Dirt and gravel are always brought in when picking and containing impurities rate is high. As a result, the impurity rate is high and it is a burden to do the following separation. The expansions spiral chili pepper harvester, the tilt arbor comb chili pepper harvester and the ribbon combs chili pepper harvester's demanding for higher line of picking has great limitation on the chili pepper plants' line spacing and thus limits the picking efficiency of the chili peppers, while the roller picking device of the spring tooth doesn't need to harvest by line of picking and it is better to pick more flexibly. Based on the above analysis, the spring tooth are determined to make the picking parts of the picking device [7-10].

\section{THE BASIC STRUCTURE AND WORKING PRINCIPLE OF THE PICKING DEVICE}

The structure of the picking device consists of the following parts as shown in Fig. (2).

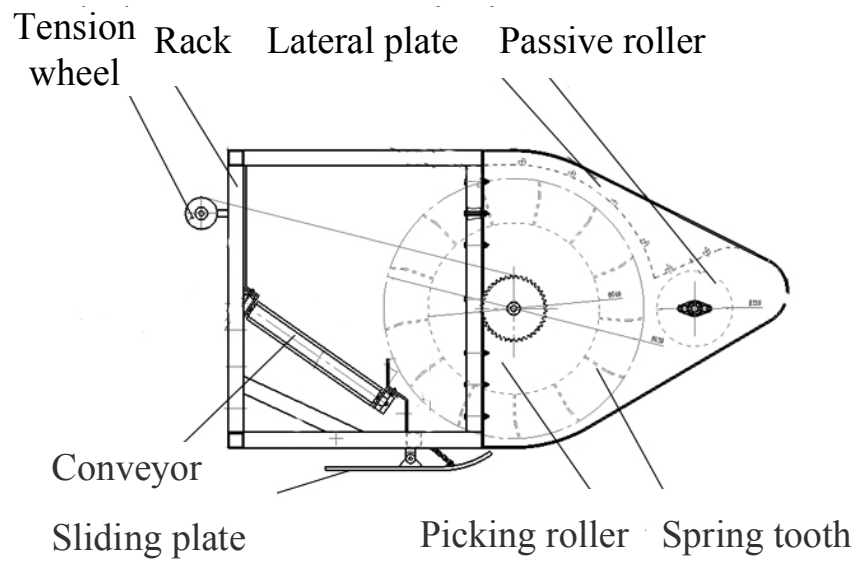

Fig. (2). Schematic diagram of the structure of the picking device.

Picking principle is explained as follows: firstly the passive wheel will slowly push the chili pepper plants forward and form a certain lodging angle, making it convenient for chili pepper continuously, slowly and stably to enter the picking device. In the process of working we can adjust the side bolt according to the height of plant to guarantee that it can rotate freely; secondly, the picking device is composed of picking roller and spring tooth. The spring tooth is fixed on the roller and the spring tooth which moves to the front screens the whole chili pepper plant by rotating clockwise and picks the chili pepper and small branches. And as the roller rotates, the chili peppers and the branches picked move backward with the force of the spring tooth and finally fall on the conveyor belt, thus the process of picking chili peppers is completed as shown in Fig. (3).

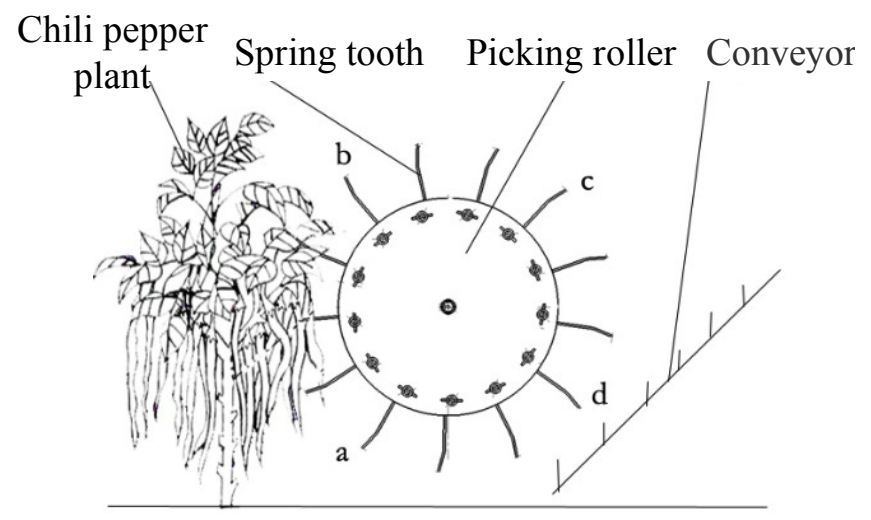

Fig. (3). Schematic diagram of the picking principle.

\section{DESIGN AND ANALYSIS ON KEY COMPONENTS OF THE PICKING DEVICE}

\subsection{Spring Tooth}

The spring tooth may suffer from intermittent load in the process of picking chili peppers, so the tail of the spring 
tooth is designed as helical spring to reduce damage by the nonuniform force. The helical spring of a spring tooth has a fixed role as shown in Fig. (4).

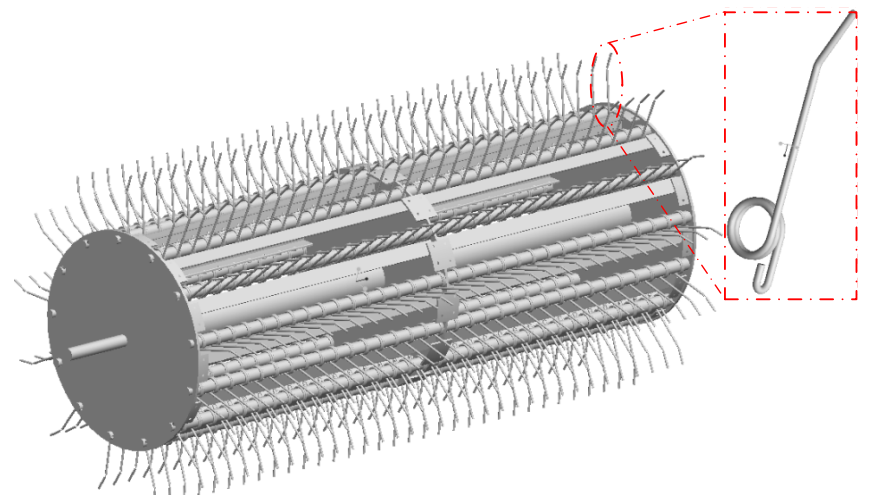

Fig. (4). The 3-D model of picking roller and a spring tooth.

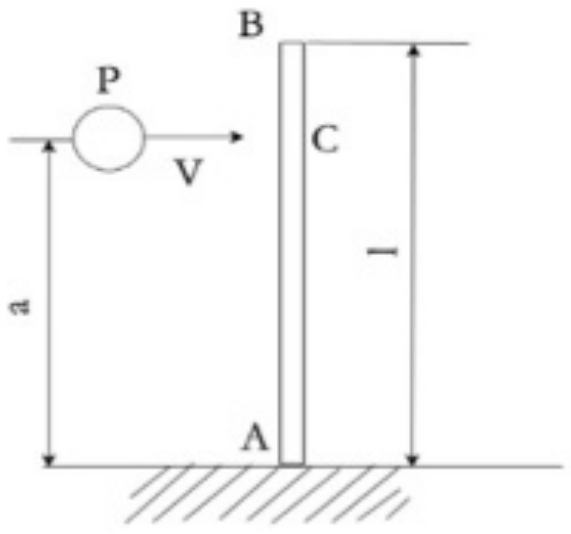

Fig. (5). Simplified impact model of a spring tooth.

The speed of the spring tooth dramatically changes while the spring tooth, chili pepper and stem contact in a very short time. The stress distribution is extremely complex in the contact region, and the impact duration is very short, therefore the contact force is difficult to accurately obtain in the short time. A simplified impact model is built as seen in Fig. (5). The bottom of the spring tooth is fixed.

The dynamic load factor is determined according to Eq.

$$
K_{d}=\sqrt{\frac{v^{2}}{g D_{s t}}}=\frac{v}{a} \sqrt{\frac{3 E I}{g a P}}
$$

where,

L---the spring tooth's length, meter;

P---the impact objects' weight, $\mathrm{Kg}$;

V---speed of the roller, $\mathrm{m} / \mathrm{s}$;

I---the moment of inertia, $\mathrm{N} \cdot \mathrm{m}$.

The maximum stress in the spring tooth refers to

$$
s_{d \max }=K_{d s_{\text {stmax }}}=\frac{V}{W} \sqrt{\frac{3 E I P}{g a}} \leq\left[\sigma_{\mathrm{d}}\right]
$$

where, $\sigma_{\text {dmax }}$---the biggest stress in the spring tooth.

$\left[\sigma_{\mathrm{d}}\right]=205 \mathrm{MPa}, \sigma_{\mathrm{dmax}}<\left[\sigma_{\mathrm{d}}\right]$ Meet the safety

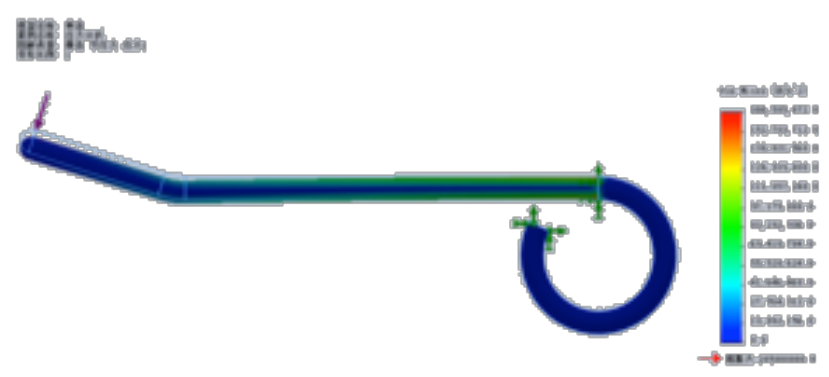

Fig. (6). Stress distribution of a spring tooth.

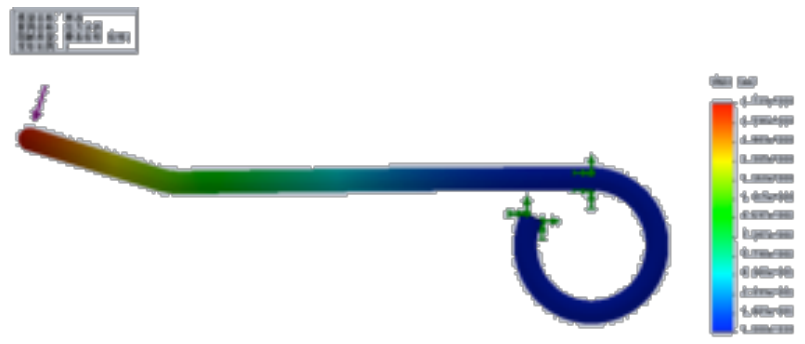

Fig. (7). Displacement of a spring tooth loaded impact force.

From Figs. $(6,7)$, the maximum stress appears in the edges of the spring tooth and the rings. The maximum stress is about $167 \mathrm{MPa}$ while the elongation stress of $\mathrm{OCr} 18 \mathrm{Ni} 9$ $\sigma_{\mathrm{p}} \geq 205 \mathrm{MPa}$, obviously $\sigma_{\max }<\left[\sigma_{\mathrm{p}}\right]$. So the spring tooth of the roller meets the design requirements. On the other hand, it can be seen from the displacement nephogram that the maximum deformation of the spring tooth occurs at the top of the spring tooth. The maximum displacement is about $2 \mathrm{~mm}$, which meets the design requirements.

\subsection{The Picking Roller}

\subsubsection{The Picking Roller's Dimension}

Considering the width of rack and a modest gap between the picking roller and the guard plate, the width of the picking roller is specified as $1580 \mathrm{~mm}$. According to the agronomic characteristics of the chili pepper in Xinjiang and the factor of handful chili pepper's different height considered in degree, the outer diameter of the picking roller is identified as $525 \mathrm{~mm}$.

\subsubsection{The Rotate Speed and the Translational Speed}

The picking roller rotates around axis with angular velocity $\bar{\sigma}$ and the harvester step forward with a translational speed $v$, which makes the M point on the top of the spring tooth do horizontal movement as well as rotating in a circle. Based rectangular coordinate system in Fig. (8), $\mathrm{M}$ point's motion equation is written as follows:

$\left\{\begin{array}{l}x=(R+L) \cos \alpha+v t \\ y=(R+L) \sin \alpha \\ \alpha=\varpi t\end{array}\right.$

where, 
$x$---M-point's abscissa;

$y$---M-point's ordinate;

$R$---the radius of the picking roller;

$L$---the radial distance of the spring tooth out of a roller.

It can obtain M-point's the equations of velocity and acceleration by making first derivative and second derivative for M-point's displacement equations:

$\left\{\begin{array}{l}x^{\prime}=-\varpi(R+L) \sin \varpi t+v \\ y^{\prime}=\varpi(R+L) \cos \varpi t \\ v_{m}=\sqrt{x^{\prime 2}+y^{\prime 2}}\end{array}\right.$

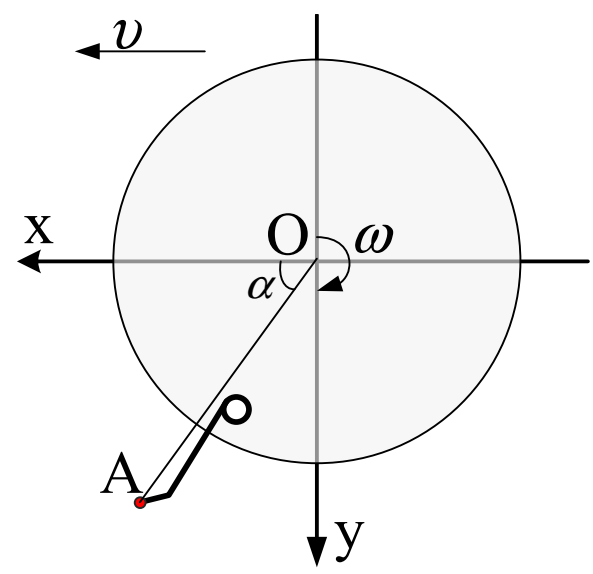

Fig. (8). The Flat structure sketch of the spring tooth.

The translational speed is determined as $0.3 \mathrm{M} / \mathrm{s}, 0.7 \mathrm{~m} / \mathrm{s}$, $2.0 \mathrm{~m} / \mathrm{s}$ and the rotate speed is determined as $50 \mathrm{r} / \mathrm{min}$, 138r/min, 200r/min. Picking a chili pepper needs at least five spring teeth. By setting 9 different groups of rotation speed and translational speed, trajectory curves can be simulated by ADAMS software as shown in Fig. (9).

According to the simulation results, the movement trajectories of five spring tooth at their top can be clearly shown and the optimal translational speed and rotation speed can be judged from the overlapped level of the areas within these trajectories.

From Fig. (9), picking demands are entirely not met when the translational speed is $2.0 \mathrm{~m} / \mathrm{s}$ and the rotation speed is $50 \mathrm{r} / \mathrm{min}$. The translational speed is much fast, at the same time the rotate speed is fast too, but it can be seen that the overlapped area is not enough. To meet the condition that five spring tooth sweep a plant, it's necessary to increase the rotate speed higher, which will require highly on the power sources of the picking device to increase the cost. Therefore, the translational speed cannot be larger than $2.0 \mathrm{~m} / \mathrm{s}$.

When the translational speed is $0.3 \mathrm{~m} / \mathrm{s}$, the overlapped level is extremely high at three different rotate speeds. They all meet the requirement that at least five spring teeth sweep the fruit area of a chili plant. There are more number of the spring teeth which sweep a chili plant at the same time at the speed of $138 \mathrm{r} / \mathrm{min}$ or $200 \mathrm{r} / \mathrm{min}$ especially. It's conductive to pick all the chili peppers. In the two cases, it will spend more time picking for a plant because the translational speed is slow. On the other hand, it is likely to pick chili pepper leaves if the rotate speed is too fast. Therefore it is ideal group with $0.3 \mathrm{~m} / \mathrm{s}$ translational speed and $50 \mathrm{r} / \mathrm{min}$ rotate speed simultaneously.

The case that the translational speed is $0.7 \mathrm{~m} / \mathrm{s}$ and the rotate speed is $50 \mathrm{r} / \mathrm{min}$ does not meet the requirements. The
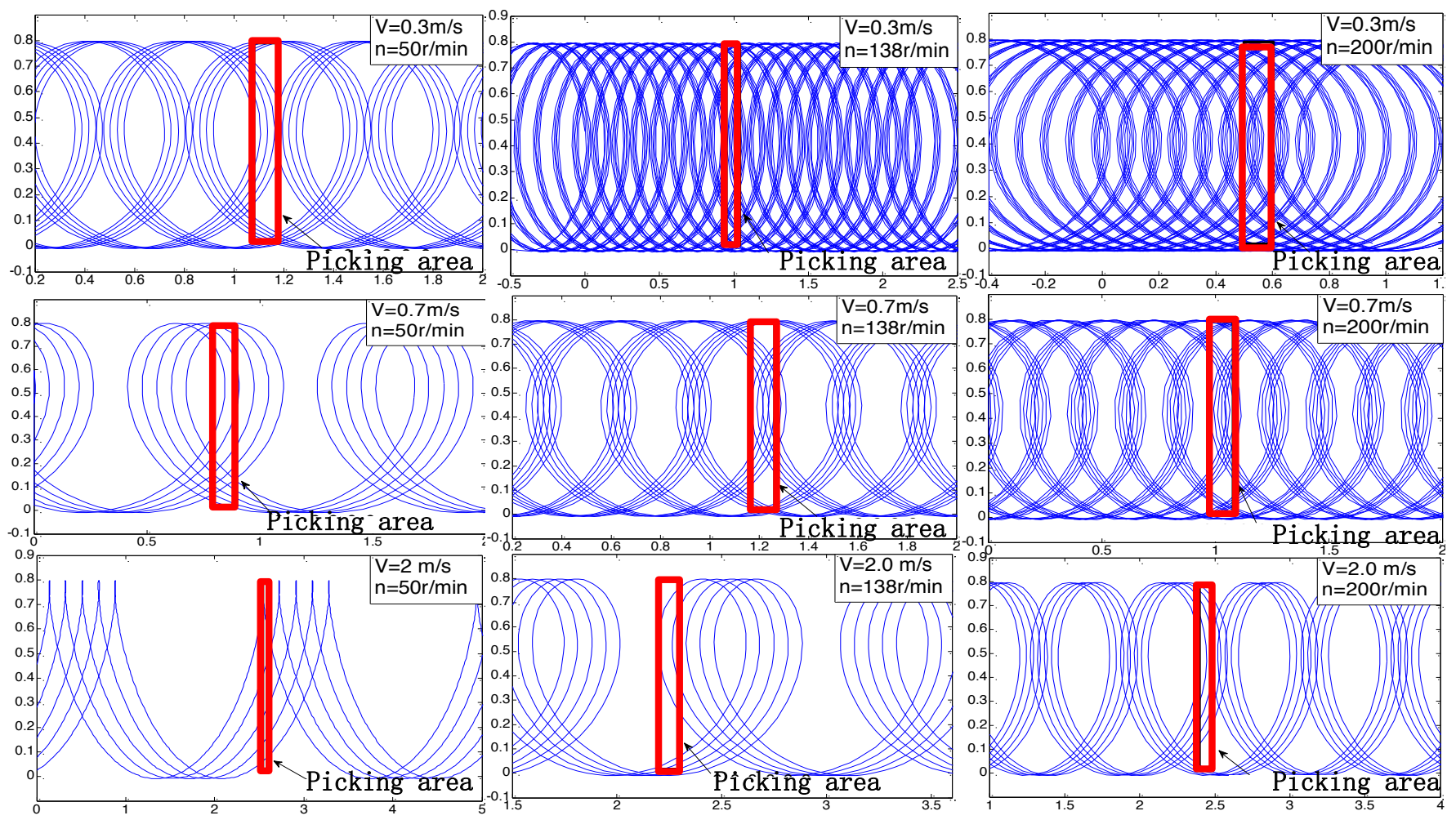

Fig. (9). Trajectory graphs of five spring teeth at different translation speeds and rotate speeds. 
reason is only three or four spring teeth will sweep a plant in the condition. It can be seen the overlapped level is good with the rotate speed is $200 \mathrm{r} / \mathrm{min}$ or $138 \mathrm{r} / \mathrm{min}$. But the same problem is when the rotate speed reaches $200 \mathrm{r} / \mathrm{min}$, the overlapped level is good. While the picking efficiency is lower than the case at the $138 \mathrm{r} / \mathrm{min}$ rotate speed, chili leaves may be picking together. Therefore the translational speed at $0.7 \mathrm{~m} / \mathrm{s}$ and the rotate speed at $138 \mathrm{r} / \mathrm{min}$ are better ideal.

In view of work efficiency with the same net rate, the translational speed at $0.7 \mathrm{~m} / \mathrm{s}$ and the rotate speed at 138 $\mathrm{r} / \mathrm{min}$ is optimal.

\subsection{The Passive Roller}

There are two passive rollers and their diameter are $200 \mathrm{~mm}$ and $150 \mathrm{~mm}$, respectively. These passive rollers are to make chili stem at a dip angle in order to neatly go into among the spring teeth of the picking roller, which makes it convenient to pick chili pepper. For the passive rollers with different heights, the bent level of chili stem is different and the effect on picking chili pepper is not the same.

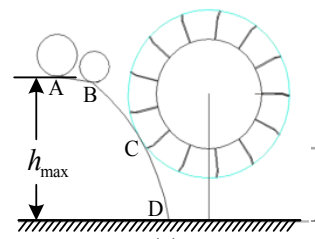

(a)

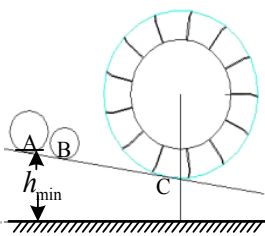

(b)

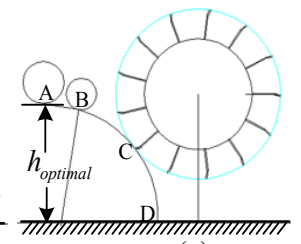

(c)
Fig. (10). Range of passive roller's height.

(1) The upper limit of passive roller height $h_{\max }$

When the length of ABCD segment is bigger than the height of chili plant, the passive rollers have not effect on picking chili pepper as shown in Fig. (10a). It is the upper limit of the passive roller height and $h_{\max }$ is $777 \mathrm{~mm}$.

(2) The lower limit of the passive roller height $h_{\text {min }}$

Two passive rollers and spring tooth have the same common tangent in Fig. (10b), which is the lower limit of passive roller height. When passive roller height less than the height, chili plant will not contact with spring tooth of the roller, and chili peppers are be able to pick. As a result, $h_{\min }$ is $421 \mathrm{~mm}$.

On the other hand, bending deflection of chili plants should not be too big, otherwise chili pepper will be broken and the production net rate will be reduced. The chili stem can be simplified to a cantilever beam. The flexivity of cantilever beam is defined as:

$\omega_{b}=-\frac{F l^{3}}{3 E I}$

According to the mechanical characteristics of chili stem, the elasticity modulus of the chili stem $E$ is 400 . The height of chili stem $l$ is $990.3 \mathrm{~mm}$. From Eqn. (1), the maximum allowed flexivity is obtained. The maximum flexivity of the chili stem is $568 \mathrm{~mm}$ during the actual picking, which meets the design requirement.

(3) The optimal passive roller height $h_{\text {optimal }}$
When the $A B$ segment of chili stem is tangent to the BCD and the BCD segment of chili stem is tangent to the circle formed by the spring tooth's top, chili stem is fed the most smoothly and the effect of picking is the best as shown in Fig. (10c). In this case, $h_{\text {optimal }}$ above the ground is $650 \mathrm{~mm}$.

\section{TEST RESULTS}

The novel chili pepper harvester with the picking device is achieved many tests in Xinjiang farm. Fig. (11) is the photo of the chili pepper harvester with picking device, which is picking chili pepper on farm. These test results are summarized in Table 1. From Table 1, the main test results have reached the design demand.

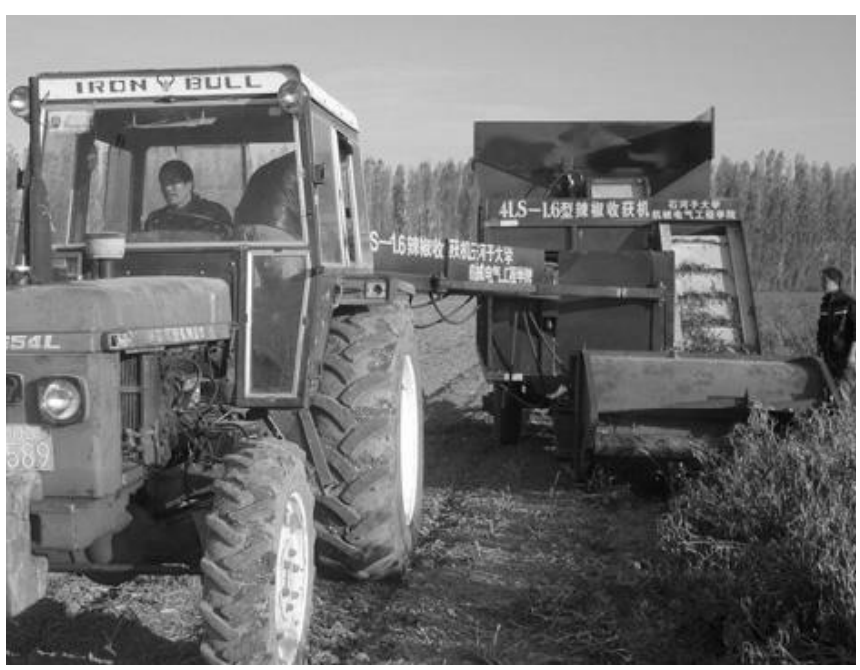

Fig. (11) The photo of the chili pepper harvester's picking test on farm.

Table 1. Picking test results of the chili pepper harvester.

\begin{tabular}{|c|c|c|}
\hline Parameter & Design Demand & Test Result \\
\hline \hline Total loss rate (\%) & $\leq 8$ & 5.15 \\
\hline Damage rate (\%) & $\leq 5$ & 3.22 \\
\hline Picking rate (\%) & $\geq 95$ & 99.15 \\
\hline Productivity $(\mathrm{t} / \mathrm{h})$ & 25 & 34.50 \\
\hline
\end{tabular}

\section{CONCLUSION}

Based on the working principle of the chili pepper harvesters' picking device, the structure design, modelling and simulation for key components of picking device is presented in detail, the main conclusions are as follows:

(1) By comparing the disadvantages and advantages of all kinds of picking devices, the roller with spring tooth of picking device don't need to line during picking, and there is a better flexibility and effect of picking.

(2) These works for a spring tooth such as structure design, stress analysis, strength check, which demonstrates the design meets picking requirement; 
(3) The optimal group is translational speed at $0.7 \mathrm{~m} / \mathrm{s}$ and the rotate speed at $138 \mathrm{r} / \mathrm{min}$ through the simulation of trajectory curve's picking area from motion trajectory equation of the spring tooth;

(4) Finally, the height of the passive rollers is analyzed and the range of height is $421 \mathrm{~mm}$ to $777 \mathrm{~mm}$, and the optimal height is $650 \mathrm{~mm}$.

\section{CONFLICT OF INTEREST}

The author confirms that this article content has no conflict of interest.

\section{ACKNOWLEDGMENTS}

This work is financially supported by the Natural Science Foundation of China (51165041) and China Postdoctoral Science Foundation Funded Project (2013M542055).

\section{REFERENCES}

[1] X.Z. Dai, Z. M. Liu. "On Current Situation and its Development Trends of the Pepper Industry in China," Journal of China Capsicum, vol. 4, pp. 1-6, 2015.

[2] Y.C Chen, X.Y Qin, et al. "The Simulation of the Planting Movement for the Dibble-Type Transplanter," Applied Mechanics and Materials. Vol. 130-134, pp. 519-523, Oct. 2011.
[3] X.Y Qin, J Lei, Y.C Chen. "Design and Research on Key Components of a novel self-propelled Chili Pepper Harvester," Advanced Materials Research, vol. 468-471, pp. 794-797, Feb. 2012.

[4] Norman Watenpaugh, Gilroy, Calif. Pepper Harvesting Machine: United States, 4402175, 1983-09-06.

[5] P.A.Funk, S. J.Walker. "Evaluation of five Green Chile cultivars Utilizing and five different harvest mechanicas," American Society of Agricultural and Biological Engineers, vol. 26(6), pp. 955-964, 2010 .

[6] S.B Shooter, K.W. Buffinton. "Design and development of the Pik Rite chili pepper harvester: a collaborative project with the university, Industry, and government," ASEE/IEEE, vol. 2, pp. 1924, 1999.

[7] Y.C Chen, S.J Hu and F.Q Zhang, "The research on analysis and simulation of planting movement for the dibble-type transplanter," ICMPMT 2011, chengdu, 2011, pp. 70-74.

[8] L. Wang, T.J Kazmierski and B.M. Al-Hashimi, "Integrated approach to energy harvester mixed technology modelling and performance optimisation," Design, Automation and Test in Europe, pp. 704-709. 2008.

[9] T.T Liu, S.L Hou and X. Zhao, "Computer Aided Analysis of Planting Mechanism of the Seedling Transplanter", Measuring Technology and Mechatronics Automation, ICMTMA, Zhangjiajie, 2009, pp. 38-41.

[10] A.P Chatzimichali, I.P Georgilas and V.D T, "Design of an advanced prototype robot for white asparagus harvesting," Advanced Intelligent Mechatronics, IEEE/ASME, Singapore, 2009, pp. 887-892. 